the expensive hardware of last year is this year's dusty junk. (3) Above all, beware of creating more than one master copy of the latest version. If the text you have spent all day revising does not include yesterday's hard worked changes but is based instead on an earlier, unrevised version, hours of human effort will be necessary to merge the two sets of modifications into a single useful master copy.

In maternity care two further fundamental warnings apply: beware lest technology is introduced for its own sake, not because it truly improves patients' care; and choice and consumer power come from openness, not from black stripes and inaccessible microchips.

All these principles seem to have been forgotten in moves towards using smart cards as an advance in the provision of maternity care. Such cards are unreadable without expensive technology, too vulnerable to damage or destruction to be used as the master copy, and cannot be used as the master copy because they are not immediately accessible for updating. The use of one of several different types of smart or optical card will too easily lead to a further waste of scanty health resources; other industries should be taking the risks entailed in the standardisation of smart card technology. The electronic master copy of the antenatal record ought to be in the primary health centre frequently backed up, and regularly updated by modem from a variety of other sources and possibly eventually (with potential problems borne in mind) from hand held, mobile devices for collecting data.

Possibly the only reasonable use of a smart card might be as a personally held identification key. If it was available in a clinic such a card would automatically minimise the risk of one mother's data being erroneously entered into another mother's electronic record.

RUPERT FAWDRY Consultant obstetrician and gynaecologis Milton Keynes General Hospital, Milton Keynes MK5 6LD

1 Drife JO. Assessing the consequences of changing childbirth $B M f$ 1995;310:144-5. (21 January.)

\section{Management of the irritable bowel syndrome}

\section{Early reassurance is important part of treatment}

EDITOR,-Recent articles have discussed the management of the irritable bowel from several points of view. R C Spiller argues for a predominantly medical approach to treatment once the hurdles of reassurance and dietary advice have been negotiated, ${ }^{1}$ while Francis Creed emphasise the importance of psychological treatments for selected groups of patients. ${ }^{1}$ Michael J G Farthing explores the relations between the bowel, body, and brain and provides further advice about the importance of making an early, positive diagnosis and of avoiding overinvestigation. ${ }^{2}$

Perhaps the most important moment for patient with the irritable bowel syndrome is the moment when he or she decides to make the first contact with general practice. We know from community based studies that the prevalence of the syndrome in the general population is roughly $20 \%$ but that only between a quarter and a third of patients consult general practitioners. ${ }^{3}$ Work in North America and Britain has shown that the severity and frequency of symptoms alone poorly predict the likelihood of consultation and that concerns that the symptoms represent a serious disease and specific worries about cancer explain much of the difference between those who do and do not consult. ${ }^{4}$ Patients who consult are more likely to have abnormal levels of anxiety and clinical depression than people with the syndrome in the community, in whom affective disorders are much less commonly seen.

This means that we have to provide reassurance. Reassurance requires a direct confrontation of patients' anxieties about cancer and serious disease and an exploration of these beliefs if they are not immediately apparent. Unless this happens early in the course of the medicalisation of the syndrome, further attempts at reassurance, accompanied by repeated negative results of investigations, will probably serve simply to increase anxiety and apprehension about the symptoms and their underlying cause.

The corollary is that initial treatment needs to embrace physical and psychological approaches, and a cognitive approach to symptoms is probably more likely to be successful than a search for "treatable" affective disorders. Gomborone et al recently documented the negative cognition of patients with the irritable bowel syndrome, ${ }^{5}$ and a randomised controlled trial of an early cognitive therapeutic intervention in the syndrome, starting as soon as possible after the first contact with general practice, seems worth while.

ROGER JONES

Department of General Practice,

Division of Primary Health Care,

UMDS,

London SE11 6SP

1 Spiller RC, Creed F. Irritable bowel or irritable mind? $B M \mathcal{F}$ 1994;309:1646-8. (17 December.)

2 Farthing MJG. Irritable bowel, irritable body, or irritable brain? BMF 1995;310:171-5. (21 January.)

3 Jones $R$, Lydeard $S$. Irritable bowel syndrome in the general population. $B M F$ 1992;304:87-90.

4 Kettell J, Jones $R$, Lydeard $S$. Reasons for consultation in irritable bowel syndrome: symptoms and patient characteristics. Br $\mathcal{G}$ Gen Pract 1992;42:459-61.

5 Gomborone JE, Dewsnap PA, Libby GW, Farthing MJG. Selective affective biasing in recognition memory in irritable bowel syndrome. Gut 1993;34:1230-3.

\section{Food intolerance may play a part}

EDrToR,-In his review on the irritable bowel syndrome Michael J G Farthing ignores the evidence that symptoms can, in many cases, be reliably attributed to food intolerance. ${ }^{1}$ As early as 1771 the King's physician, Sir George Baker, presented to the Royal College of Physicians a patient whose abdominal symptoms improved with a diet of "sea biscuits and salt meat."' During the first half of the 20th century several reports of patients with abdominal pain that responded to dietary modification were published from the United States. ${ }^{3}$ Studies have shown that as many as $70 \%$ of patients with abdominal pain and diarrhoea may be successfully managed by $\operatorname{diet}^{34}$; double blind challenges have provided objective evidence of food intolerance. As follow up of patients shows that most of them remain well on diet for long periods the value of successfully identifying food intolerance should not be dismissed. In addition, use of antibiotics (with consequent changes in the gut flora) may be an important factor in the development of the syndrome.

PETER J LEWIS

Southampton SO15 2DT Complementary physician

1 Farthing MJG. Irritable bowel, irritable body, or irritable brain? $B M F$ 1995;310:171-5. (21 January.)

Drummond JC, Wilbraham A. The Englishman's food. London: Jonathan Cope, 1959:254.

Duke WD. Food allergy as a cause of abdominal pain. Arch Inter Med 1921;28:151-65.

4 Jones VA, Hunter JO. Irritable bowel syndrome and Crohn's disease. In: Brostoff J, Challacombe SJ, eds. Food allergy and intolerance. London: Baillière Tindall, 1987:555-69.

5 Jones VA, Wilson AJ, Hunter JO, Robinson JE. The aetiological role of antibiotic prophylaxis with hysterectomy in irritable bowel syndrome. Obstet Gynaecol 1984;5(suppl 1):S22-3.

\section{Author's reply}

EDITOR,-The role of food intolerance in the production of symptoms in patients with the irritable bowel syndrome is interesting but controversial. We should not forget that both the syndrome and perceived food intolerance are common in the community, occurring in roughly a fifth of the population. ${ }^{1}$ It would therefore be expected that the two conditions would quite frequently coincide in the same person without this necessarily implying causality. Actual food intolerance, determined by double blind, placebo controlled food challenge, is reported to occur in $1-2 \%$ of the population. In a large, careful study Nanda et al found that $48 \%$ of 200 patients with the irritable bowel syndrome responded to an exclusion diet, most of whom continued with the diet because of prolonged benefits. ${ }^{2}$ More than half of the initial study group, however, did not benefit in any way. In addition, there was no correlation between the response to the exclusion diet and any particular symptom complex.

Introducing a formal exclusion diet is a substantial undertaking and can considerably disrupt normal life. Some patients with the irritable bowel syndrome are, however, keen to pursue this approach, and those who respond may find dietary restriction less of a burden than their abdominal symptoms. I certainly encourage patients to explore dietary triggers and stated this clearly in my article. I generally guide patients on the groups of foods that are most likely to be associated with abdominal symptoms, such as dairy products and grains. ${ }^{2}$ I am less enthusiastic about formal exclusion diets because I see a large number of patients who have tried this approach and in whom it has failed and because I have found that treating patients with dietary exclusion is less successful than some of the other approaches outlined in the article.

M J G FARTHING

Digestive Diseases Research Centre, London EC1M 6BQ

1 Young E, Stoneham MD, Petruckevitch, Barton J, Rona R. population study of food intolerance. Lancet 1994;343:1127-9. 2 Nanda R, James R, Smith H, Dudley CRK, Jewell DP. Food intolerance and the irritable bowel syndrome. Gut 1989;30: 1099-104.

\section{Proposed new deprivation index}

\section{Has major flaws in its derivation and validation}

EDrToR,-David C E F Lloyd and colleagues propose a new deprivation index for use in general practice, which is based on the proportion of patients exempted from prescription charges because they have a low income. It is therefore a proxy for the proportion of the practice population living in poverty. The authors believe that it has advantages over the indices with which they compare it (Jarman, Townsend, and Carstairs) namely, that it is practice based and can be frequently updated. They correlate it with the established deprivation indices, producing impressive results at health authority level but unfortunately presenting no results at the general practice level, where it is intended to be used.

There are major flaws in the derivation and validation of this index, which will adversely affect its utility as a measure of deprivation for practice populations. As the authors acknowledge, the low income category of exemption from prescription charges overlaps with other categories. For example, people on low incomes with diabetes may prefer to claim exemption on the basis of illness rather than poverty. The proposed index would thus register variation in local attitudes to poverty, with people being more likely to choose the disease option in areas where poverty is most stigmatised. Prescribing analysis and cost (PACT) data depend on the provision and quality of services, which further confound the index. 
To validate the index the authors correlate it with the level of prescribing of certain drugs, hormone replacement therapy, and tamoxifen, which they regard as indicators of the social class composition of the practice population. This procedure involves unsupported assumptions, particularly in relation to hormone replacement therapy. An underlying problem with the authors' use of PACT data is the implicit assumption that prescribing is a standardised procedure in which general practitioners diagnose and treat disease systematically. The literature does not support this assumption; indeed, it shows great variation among doctors, much of which can be explained only by personal idiosyncrasy. ${ }^{2}$ It seems dangerous to base an objective measure of deprivation on such subjective behaviour.

Although the correlation between exempted precriptions and deprivation at health authority level is high, the measure proposed by Lloyd and colleagues is intended for practice based research rather than epidemiological research on larger populations. For example, the authors suggest that it would be useful in researching topics such as prescribing. Given that PACT data are Britain's main source of prescribing data and also provide the data for the authors' deprivation index, however, this suggestion seems tautologous. Further efforts are needed to develop a reliable and valid measure of deprivation at the practice level.

NICKY BRTTTEN Lecturer in medical sociology
Department of General Practice,
United Medical and Dental Schools of Guy's and
St Thomas's Hospitals,
London SE11 6SP
MEL BARTLEY
Research officer in public health policy Nuffield College, Oxford OX1 1NF

DAVID BLANE Lecturer in medical sociology

Charing Cross and Westminster Medical School,

London W6 8RP

1 Lloyd DCEF, Harris CM, Clucas DW. Low income scheme index: a new deprivation scale based on prescribing in general practice. BMF 1995;310:165-9. (21 January.)

2 Crombie DL, Cross KW, Fleming DM. The problem of diagnostics variability in general practice. $f$ Epidemiol Community Health 1992;46:447-54.

\section{Poor correlation with Jarman index may be due to changes in deprivation since 1981}

EDITOR,-David C E F Lloyd and colleagues compare three deprivation indices-the Jarman, Townsend, and Carstairs indices-and show that the correlation between the Jarman index and the two other indices is not as good as that between the Townsend and Carstairs indices themselves. ${ }^{1}$ I note that the Townsend and Carstairs indices were based on data for 1991 whereas the Jarman index was based on data for 1981. We should not necessarily conclude that the Jarman index is less good. Perhaps the pattern of deprivation has changed over the past 10 years, explaining the slightly worse correlation between the Jarman index and the Townsend and Carstairs indices.

R S JAMES

Isle of Lewis,

Outer Hebrides

1 Lloyd DCEF, Harris CM, Clucas DW. Low income scheme index: a new deprivation scale based on prescribing in general practice. $B M F$ 1995;310:165-70. (21 January.)

\section{May perpetuate variation in prescribing unrelated to patients' need}

EDrTor,-Measures based on entitlement to free prescriptions because of low income are attractive as indices of deprivation, but there are inherent drawbacks to an index based on the number of prescriptions rather than of people receiving (or entitled to) them.

Firstly, as David C E F Lloyd and colleagues comment about their proposed low income schem index, the "deprivation score is calculable but is affected by the individual habits of prescribers." The effect is simply illustrated if different relative prescribing rates (1-3) are used for a population (population A; table). Although the effect will be most pronounced at practice level, the prescribing habits of practitioners within a family health services authority may be subject to the same local influences, with consequent effect on the proposed deprivation score at health authority level.

Effect of relative prescribing rates, demography, and proportions of people entitled to free prescriptions because of low income on low income scheme score

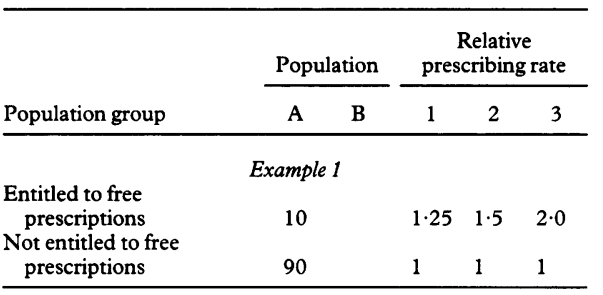

\section{Low income scheme}

score $(\%)$

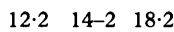

\begin{tabular}{lccc} 
& Example 2 & \\
$\begin{array}{l}\text { Entitled to free } \\
\text { prescriptions }\end{array}$ & 10 & 10 & 2 \\
$\begin{array}{l}\text { Not entitled to free } \\
\text { prescriptions: }\end{array}$ & & & \\
Aged $<65$ & 70 & 50 & 1 \\
Aged $\geqslant 65$ & 20 & 40 & 3 \\
\hline
\end{tabular}

\section{Low income scheme}

score (\%)

$13 \cdot 3 \quad 10 \cdot 5$

Secondly, the acknowledged influence of patients' age on prescribing need ${ }^{2}$ means that the value of the proposed index depends on the demography of those not exempted because of low income, which is illustrated by populations $A$ and $B$ in example 2 in the table. Note that population A, with fewer elderly people, has a higher low income scheme index for the same proportion of people entitled to free prescriptions because of low income.

By definition, the low income scheme index is strongly driven by the distribution of poverty among people of working age, and high correla tions with the Townsend, Jarman, and Carstairs indices of deprivation are therefore to be expected. All the indices have imperfections, but no absolute definition of deprivation is available as a true comparator. Indeed, the various physical and social components of deprivation may be of different relative importance, depending on the context in which the index is to be used. The low income scheme index is derived from the current distribution of prescribing resources, which is largely historic and influenced by practitioners. This may or may not make it a suitable index for studying the relation between population deprivation and the uptake of drugs, but its use in determining future allocation of resources may have the undesirable effect of perpetuating variations in prescribing unrelated to patients' need.

At family health services authority or local authority level there is potential for an index based on the Department of Social Security's rates for income support and family credit, which would be population based rather than prescription based and would take into account deprivation among elderly people and children. Whether such an index would have any substantial advantage over those already available is for debate.

SARAH J ROBERTS Wolfson Unit of Clinical Pharmacology, University of Newcastle, Newcastle upon Tyne NE2 4HH
1 Lloyd DCEF, Harris CM, Clucas DW. Low income scheme index: a new deprivation scale based on prescribing in genera practice. $B M 7$ 1995;310:165-70. (21 January.)

2 Roberts SJ, Harris CM. Age, sex and temporary residen originated prescribing units (ASTRO-PUs): new weighting for analysing prescribing of general practices in England. $B M$ 1993;307:485-8.

\section{Authors' reply}

EDITOR,-Nicky Britten and colleagues say that we did not validate our index at practice level in the way that we did at family health services authority level. This would have required the postcode of every patient; not only is this impractical but we have already established, in a paper submitted for publication, that attributing census data to practices can give severely misleading results. $\mathrm{R} \mathrm{S}$ James' comment, although possibly true, is not relevant until Jarman figures based on the 1991 census become available.

We acknowledged the overlap between categories, exempting people from prescription charges and assumed that it would not differ significantly among areas. The table presented by Sarah J Roberts supports this assertion since a doubling of the population aged over 65 changes the index by less than $3 \%$ - an impressive demonstration of robustness. The criticism of Britten and colleagues that patients will choose a disease based category of exemption in preference to one that is income based according to the degree to which poverty is stigmatised in different areas is interesting, but there is no evidence for it. We do not understand the meaning of their sentence "Prescribing analysis and cost (PACT) data depend on the provision and quality of services, which further confound the index."

Our choice of drugs in the second part of the validation was scarcely based on dubious assumptions, given what is known about the distribution of cardiovascular disease, childhood infections, and breast cancer, and we described at some length our reason for including hormone replacement therapy. We are well aware of the variation in practices' prescribing habits, but our study was based on patients' claims, not doctors' idiosyncracies. No tautology is involved. Roberts's example 1 in the table presents changes in the index depending on assumptions about general practitioners' prescribing, but perhaps she has neglected to consider that the index is based on cost, not items. While there has been speculation that some general practitioners will prescribe cheap items for patients exempted from charges and suggest to other patients that they should buy the drugs, it is not clear that there would be a twofold difference in the resultant cost.

We agree that research needs a reliable and valid measure of deprivation at practice level (we acknowledged in our paper that our index might not be suitable for resource allocation). Despite its imperfections the low income scheme index is the best available at the moment.

DAVID CE F LLOYD Applied statistical officer CONRAD M HARRIS Director DAVID W CLUCAS Senior computer officer

Prescribing Research Unit

Leeds University Research School of Medicine, Leeds LS2 NZ

\section{Academic integrity}

\section{Proper review makes funding irrelevant}

EDITOR,-In writing on academic integrity Richard Smith discusses conflicts of interest and suggests that authors of papers in scientific journals should state their source of funding on the basis that any bias in their work may thereby be made apparent to readers. ${ }^{1}$ This seems to be logically inconsistent. 